\title{
Bibliometric analysis of Neurosciences research productivity in Saudi Arabia from 2013-2018
}

Amani H. Alhibshi, MS, PhD, Widyan A. Alamoudi, BSc, MS, Ikram Ul Haq, BA, MA, Shafiq Ur Rehman, MA, PhD, Rai K. Farooq, MS, PhD, Foziah J. Al Shamrani, MD, SBN.

\begin{abstract}

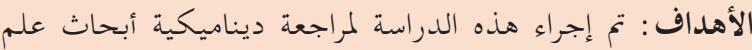

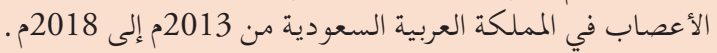

المنهجيه : البحث في قاعد تي سكوبس وسايفال عن دراسات متعلقة

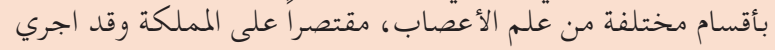

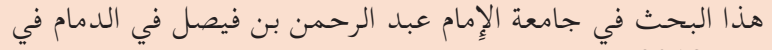

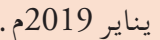

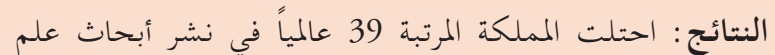

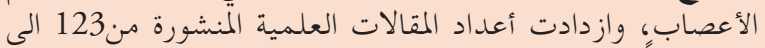

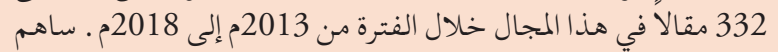

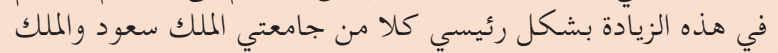

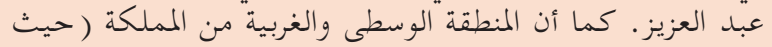

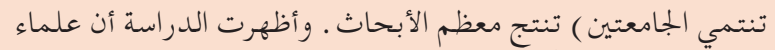

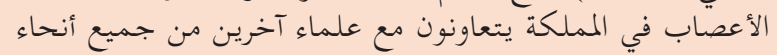

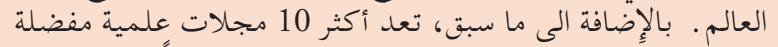

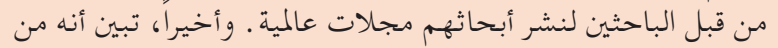

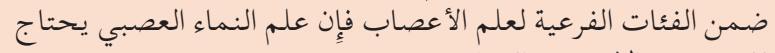

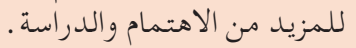

الخلاصة: تشهيد أبحاث علم الأعصاب ارتفاعاً في المملكة.

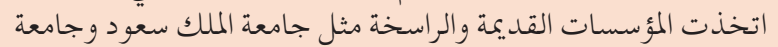

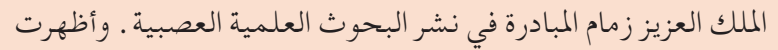

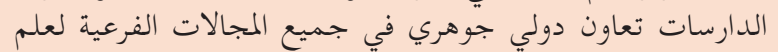

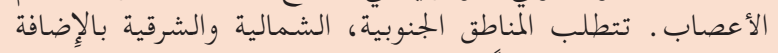

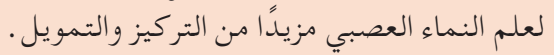

Objectives: To review the dynamics of neuroscience research in the Kingdom of Saudi Arabia (KSA) from 2013-2018.

Methods: Subject category of Neuroscience was selected in the SciVal feature of Scopus database, which includes all relevant categories of the field limiting it to Saudi Arabia.

Results: Saudi Arabia is ranked 39th in publishing neuroscientific research worldwide. The number of yearly published articles has increased from 123 to 332 during the time period between 2013 and 2018. King Saud University \& King Abdul Aziz University $\&$ their corresponding regions namely Western and Central regions are the major contributors to publications. Neuroscientists working in Saudi Arabia have collaboration with scientists from all over the world. The top 10 preferred journals are all international. In subcategories of neuroscience, developmental neuroscience seems the one that needs attention.

Conclusion: Neuroscience research is on the rise in KSA. Older and well-established institutions like King Saud University \& King Abdul Aziz University have taken lead in publishing neuroscientific research. International collaboration in all subfields of neuroscience is substantial. Eastern Southern and Northern regions and developmental neuroscience require more focus and funding.

Neurosciences 2020; Vol. 25 (2): 134-143 doi: 10.17712/nsj.2020.2.20190087

From the Department of Neuroscience Research (Alhibshi, Alamoudi, Faroog), Institute for Research and Medical Consultations, Deanship of Library Affairs (Rehman), Imam Abdulrahman Bin Faisal University, and from the Department of Neurology (Al Shamrani), Imam Abdulrahman Bin Faisal University, King Fahd University Hospital, Dammam, and from the College of Dentistry (Ul Haq), King Saud bin Abdulaziz University for Health Sciences, King Abdullah International Medical Research Centre, Riyadh, Kingdom of Saudi Arabia.

Received 8th November 2019. Accepted 11th February 2020.

Address correspondence and reprint request to: Dr. Shafiq Ur Rehman, Deanship of Library Affairs, Imam Abdulrahman Bin Faisal University, Dammam, Kingdom of Saudi Arabia.E-mail: suRehman@iau.edu.sa ORCID ID: https://orcid.org/0000-0002-8169-0132

E ducation and research are the cornerstones that form the basis of sustainable growth in a country. Concepts such as knowledge-based economy and bioeconomy have become popular in the 21 st century. ${ }^{1}$ University-industry collaborations and protection 
of intellectual property rights have given a boost to scientific research and development. ${ }^{2}$ The progress in scientific research requires periodic review. Reviewing existing government policies allows for more flexibility in the adaptation to ever-varying economic and developmental conditions. ${ }^{3}$ Health and medical research are among the pillars of the scientific advancement of a country, given the challenges of global healthcare. Of all the subfields of medical research, neuroscience research is the most interesting and challenging one. ${ }^{4}$ The term neuroscience encompasses research in the fields of clinical specialities such as neurology, neurosurgery, neuropsychiatry, and psychology as well as non-clinical disciplines such as neurobiology and neurochemistry. It also includes non-medical fields, including biomedical imaging, physics, computer science, and artificial intelligence. Hence, the field of neuroscience is of great significance to the public health as well as a technical advancement perspective. ${ }^{5}$

The Kingdom of Saudi Arabia (KSA) is transitioning to self-sufficiency and knowledge-based economy by 2030 . With one of the largest economies of the world, the KSA is giving high priority to the health and education sectors. Saudi universities have already achieved higher international rankings among educational institutions. ${ }^{6}$ Eight Saudi universities have been included in Quacquarelli Symonds' (QS) 2019 world ranking.

Bibliometric assessment is a method used to examine published scientific research contributed by individuals, institutions, and countries. ${ }^{7,8}$ It also examines the collaboration between scientists across borders. Additionally, bibliometric studies take into account the indicators of quantity, as well as quality, of research of a country or field in a given period. Further, this method of assessment can be used to review the results of the implementation of a certain change in policy in a given time frame. ${ }^{9}$ Bibliometric assessment may also be used to extract data regarding a specific subfield or an individual database or journal. These techniques can then be utilized to examine the dynamics of international collaboration, prevailing trends in research, the most productive authors and institutions, journals of preference, and authorship and collaboration patterns. Such studies can be used to direct future guidelines for researchers, academic institutions,

Disclosure. Authors have no conflict of interests, and the work was not supported or funded by any drug company. policymakers, and their funding organizations.

An action plan established by the World Health Organization indicated that there is a worldwide increase in neurological and mental disorders, causing a global burden and leading individuals and families into poverty. One of the action plan's objectives is to direct efforts towards strengthening research and healthcare in the fields of neuroscience. ${ }^{10}$ Neuroscience research will allow the generation of new knowledge that will enable the prevention of diseases, reduction of the cost of treatment, and finding new therapeutics, thus opening the way for new possibilities in this field. A bibliometric study of neuroscience productivity worldwide has documented a rapid growth of published research during the last 30 years. ${ }^{11}$ Aware of the importance of neuroscience, researchers from around the world and in the Middle East are conducting bibliometric studies on this topic to provide a solid foundation for policymaking and strategy planning in the society's neuroscientific research.

The KSA is leading the Arab world in many of the parameters of education and healthcare research. ${ }^{12}$ Previous bibliometric analyses carried out in a variety of fields have yielded valuable data. For example, one such bibliometric analysis measured computer science research publications carried out between 1978-2012 and found out that King Fahad University of Petroleum and Minerals (KFUPM) and King Saud University (KSU) were the most active institutions contributing $70 \%$ of all publications. ${ }^{13}$ Another similar study examined research publications during and after an outbreak of Middle East respiratory syndrome coronavirus (MERS-CoV) in the KSA during 2013-2014. ${ }^{14}$ Yet another bibliometric study ${ }^{15}$ presented useful findings regarding research collaboration and publication patterns of Egyptian health scientists.

Trends in neuroscience research have been reviewed as a subject of bibliometric analysis in different parts of the world under different keywords, including mental health research, stroke, and epilepsy. Moreover, neuroscience was included in the evaluation studies of biomedical research in the KSA. ${ }^{16,17}$ One such study covering clinical neuroscience ranked the KSA 40th in the world and 4th in the Middle East, highlighting a certain dearth of physician-scientists. ${ }^{18}$ Another study focusing on neurology lauded important achievements in published research in this field in Saudi Arabia and also highlighted gaps in the quality of research. ${ }^{19}$

Previous studies are restricted in their scope $e^{20,21}$ or domain $^{22}$ and are limited to a city or an institution ${ }^{23}$ in addition to the terms of consulted databases. In 
contrast, present study was conducted using the most comprehensive database of global literature, Scopus, including all the basic and clinical aspects of neuroscientific research carried out in the KSA from 2013 to 2018. The main objectives of this study were to examine the publishing trends of Saudi neuroscience researchers, the most productive and frequently cited authors, institutes and journals, and authorship and collaborative patterns. We also examined subject dispersion under the umbrella term of neuroscience.

Methods. This bibliometric analysis was carried out on the research productivity in the field of Neuroscience conducted by scientists working in or affiliated with institutions in the KSA, including Saudi nationals as well as expatriates. A bibliometric study involves cross

Table 1 - Number of Neuroscience articles produced by Saudi Arabia affiliated researchers compared with top 10 countries in this category during 2013-2018.

\begin{tabular}{lcccccccc}
\hline Rank & Country & $\mathbf{2 0 1 3}$ & $\mathbf{2 0 1 4}$ & $\mathbf{2 0 1 5}$ & $\mathbf{2 0 1 6}$ & $\mathbf{2 0 1 7}$ & $\mathbf{2 0 1 8}$ & Total \\
\hline 1 & United States & 23483 & 25195 & 25096 & 25520 & 26179 & 27582 & 153055 \\
2 & China & 5606 & 6049 & 6854 & 8368 & 8648 & 10664 & 46189 \\
3 & United Kingdom & 6558 & 6814 & 7114 & 7222 & 7531 & 8106 & 43345 \\
4 & Germany & 6115 & 6449 & 6370 & 6882 & 6869 & 7220 & 39905 \\
5 & Canada & 4109 & 4349 & 4434 & 4374 & 4625 & 5052 & 26943 \\
6 & Italy & 3702 & 3762 & 3913 & 3940 & 4060 & 4367 & 23744 \\
7 & Japan & 3541 & 3579 & 3662 & 3448 & 3569 & 3928 & 21767 \\
8 & Australia & 2870 & 3189 & 3223 & 3483 & 3568 & 3910 & 20243 \\
9 & France & 3107 & 3114 & 3271 & 3225 & 3557 & 3578 & 19852 \\
10 & Netherlands & 2397 & 2627 & 2584 & 2580 & 2678 & 2999 & 15865 \\
39 & Saudi Arabia & 123 & 272 & 265 & 262 & 310 & 332 & 1564 \\
\hline
\end{tabular}

Table 2 - Research productivity in neuroscience by institutions in Saudi Arabia during 2013-2018.

\begin{tabular}{|c|c|c|c|c|c|c|}
\hline Rank & Institutions & $\begin{array}{c}\text { Publications } \\
(\%)\end{array}$ & Region & Citations & Authors & Citations Impact \\
\hline 1 & King Abdulaziz University & $571(36.43)$ & Western & 8461 & 347 & 14.8 \\
\hline 2 & King Saud University & $380(24.29)$ & Central & 3252 & 523 & 8.5 \\
\hline 3 & King Abdullah University of Science and Technology & $101(6.44)$ & Western & 138 & 134 & 13.7 \\
\hline 4 & Alfaisal University & $99(6.31)$ & Central & 1676 & 144 & 16.9 \\
\hline 5 & Imam Abdulrahman Bin Faisal University & $69(4.40)$ & Eastern & 219 & 67 & 3.2 \\
\hline 6 & King Saud bin Abdulaziz University for Health Sciences & $67(4.27)$ & Central & 301 & 103 & 4.5 \\
\hline 7 & King Khalid University & $43(2.74)$ & Southern & 276 & 55 & 6.4 \\
\hline 8 & Taibah University & $29(1.85)$ & Western & 199 & 35 & 6.9 \\
\hline 9 & Umm Al Qura University & $21(1.34)$ & Western & 93 & 34 & 4.4 \\
\hline 10 & King Faisal University & $20(1.27)$ & Eastern & 144 & 28 & 7.2 \\
\hline 11 & Jazan University & $19(1.21)$ & Southern & 232 & 35 & 12.2 \\
\hline 12 & King Abdulaziz City for Science and Technology & $15(0.95)$ & Central & 71 & 22 & 4.7 \\
\hline 13 & University of Hail & $15(0.95)$ & Central & 69 & 14 & 4.6 \\
\hline 14 & King Fahd University of Petroleum and Minerals & $14(0.89)$ & Eastern & 129 & 19 & 9.2 \\
\hline 15 & Qassim University & $13(0.82)$ & Central & 44 & 20 & 3.4 \\
\hline 16 & Taif University & $13(0.82)$ & Western & 13 & 22 & 1 \\
\hline 17 & Prince Sattam Bin Abdulaziz University & $13(0.82)$ & Central & 21 & 13 & 1.6 \\
\hline 18 & Al-Imam Muhammad Ibn Saud Islamic University & $7(0.44)$ & Central & 21 & 7 & 3 \\
\hline 19 & Princess Nourahbint Abdulrahman University & $7(0.44)$ & Central & 15 & 7 & 2.1 \\
\hline 20 & Najran University & $7(0.44)$ & Southern & 44 & 11 & 6.3 \\
\hline 21 & University of Jeddah & $6(0.38)$ & Western & 17 & 3 & 2.8 \\
\hline 22 & Al Baha University & $4(0.25)$ & Southern & 0 & 5 & 0 \\
\hline 23 & Al Jouf University & $2(0.12)$ & Northern & 3 & 3 & 1.5 \\
\hline 24 & Northern Borders University & $1(0.06)$ & Northern & 10 & 1 & 10 \\
\hline
\end{tabular}


sectional research design that focuses on data in a given time period that is harvested on a single point of time. The SciVal feature of the Scopus database was used at Imam Abdulrahman Bin Faisal University (IAU), Dammam Saudi Arabia from January 10, 2019, to May 30, 2019. Scopus is the largest abstract and citation database of peer-reviewed literature. The sample size under study was data generated during a period of 6 years, from January 2013 to December 2018. Targeted data were exported on January 10, 2019; thus, the database was last updated on December 14, 2018. The methodology used for data retrieval from SciVal is as follows. In the main browsing menu of SciVal, we selected the country, i.e. Saudi Arabia. We selected the Subject Area "Neuroscience" which covers its subcategories such as General Neuroscience, Behavioral Neuroscience, Biological Psychiatry, Cellular and Molecular Neuroscience, Cognitive Neuroscience, Developmental Neuroscience, Endocrine, and Autonomic Systems, Neurology, Neuroscience (miscellaneous) and Sensory Systems.

All publication categories, including journal articles, book chapters, books, and conference papers were included in the analysis. Publications performed by at least one author with affiliation to a Saudi Arabian research institution were selected. Neuroscience related publications by Saudi affiliated researchers that were published before January 1, 2013 or after December 31, 2018 were excluded. The results were exported into Microsoft Excel format. The accuracy of the data, including duplication (3 dulicate records were removed), reliability, and relevance, was ensured by the repetition of the same method by another author using the same parameters. This study did not require ethical approval as the targeted data is publicly accessible in Scopus database and there is no human subject involved.

Results. Saudi Arabian affiliated authors produced 118,663 documents during 2013-2018, with an average of 19,777 documents per year and an average annual growth rate of $6.88 \% / y r$. These documents were divided into 27 broad categories/subjects. The highest numbers of documents were found in the Engineering Sciences $(\mathrm{n}=24,082 ; 20.29 \%)$ followed by Medicine $(\mathrm{n}=22,940 ; 19.33 \%)$ and Chemistry $(\mathrm{n}=18,479$; $15.57 \%)$. The lowest number of publications $(\mathrm{n}=664$; $0.55 \%$ ) were on the subject of Veterinary Science. The subject of Neuroscience research is ranked 20th with $1564(1.32 \%)$ publications.

The six-year comparison of neuroscience research productivity of KSA showed a gradual increase. Additionally, the KSA ranked 39th in global neuroscience publications output (Table 1).

The SciVal feature of the Scopus database identified 24SaudiArabian institutions that produced neuroscience related research in the specified period (Table 2). King Abdulaziz University (KAU) was the most productive institution, with 571 (36.4\%) documents produced by 347 authors. These publications received 8461 citations with an average of 14.8 citations per document. The

Table 3 - Top 15 most productive neuroscience authors affiliated with Kingdom of Saudi Arabia during 2013-2018.

\begin{tabular}{|c|c|c|c|c|c|}
\hline Ranks & Name of Author & Affiliation & Publications & $\begin{array}{c}\text { Total } \\
\text { Citations }\end{array}$ & Citation Impact \\
\hline 1. & Kamal, Mohammad Amjad & King Abdulaziz University & 78 & 683 & 8.8 \\
\hline 2. & Alsaadi, Fuad Eid S. & King Abdulaziz University & 65 & 1123 & 17.3 \\
\hline 3. & Al- Ayadhi, LailaYousef & King Saud University Medical College & 36 & 424 & 11.8 \\
\hline 4. & Liu, Yurong & King Abdulaziz University & 32 & 819 & 25.6 \\
\hline 5. & Alsaedi, Ahmed & King Abdulaziz University & 31 & 300 & 9.7 \\
\hline 6. & Ashraf, GhulamMd & King Abdulaziz University & 22 & 156 & 7.1 \\
\hline 7. & Abuzenadah, Adel Mohammed & King Abdulaziz University & 19 & 203 & 10.7 \\
\hline 8. & Attia, Sabry Mohamed & King Saud University College of Pharmacy, & 19 & 133 & 7 \\
\hline 9. & Bakheet, SalehAbdulrahman I. & King Saud University College of Pharmacy, & 19 & 133 & 7 \\
\hline 10. & El-Ansary, Afaf Kamal E. & King Saud University & 19 & 179 & 9.4 \\
\hline 11. & Nadeem, Ahmed & King Saud University College of Pharmacy, & 19 & 133 & 7 \\
\hline 12. & Al-Qahtani, Mohammed Hussain & King Abdulaziz University & 17 & 100 & 5.9 \\
\hline 13. & Bashir, Shahid & King Fahad Specialist Hospital, Dammam, & 17 & 95 & 5.6 \\
\hline 14. & Fayaz Ahmad, Sheikh & King Saud University College of Pharmacy, & 17 & 132 & 7.8 \\
\hline 15. & Bahammam, Ahmed Salem O. & King Saud University Medical College & 16 & 264 & 16.5 \\
\hline
\end{tabular}


KSU was the next most productive institution with 380 (24.3\%) documents contributed by 523 authors. The citation impact of KSU was relatively low (8.5 citations per document). King Abdullah University of Science and Technology was the third most productive institution 101 (6.44\%) while Alfaisal University was the 4th most productive institution with 134 authors producing 99 $(6.3 \%)$ documents that received the highest citations impact (16.9 citations per document). These are only three institutions that exceeded 100 publications. Three institutions, including Alfaisal University, produced 50 to 100 publications on the subject of neuroscience while eighteen institutions produced less than 50 publications (Table 2).

The region-wise analysis indicated that among the five regions of KSA, researchers affiliated with the

Table 4 - Twenty most frequently collaborative countries with Kingdom of Saudi Arabia in the field of neuroscience during 2013-2018.

\begin{tabular}{|c|c|c|c|c|c|}
\hline Rank & Country & $\begin{array}{l}\text { Co-authored } \\
\text { publications }\end{array}$ & Citations & Citations per Publication & Institutions \\
\hline 1 & United States & 190 & 1872 & 9.8 & 160 \\
\hline 2 & China & 166 & 3546 & 21.4 & 83 \\
\hline 3 & United Kingdom & 88 & 1623 & 18.4 & 64 \\
\hline 4 & Canada & 85 & 865 & 10.2 & 18 \\
\hline 5 & Egypt & 68 & 467 & 6.9 & 25 \\
\hline 6 & India & 58 & 857 & 14.7 & 34 \\
\hline 7 & Switzerland & 49 & 1056 & 21.6 & 10 \\
\hline 8 & Pakistan & 46 & 561 & 12.2 & 13 \\
\hline 9 & Australia & 41 & 676 & 16.5 & 41 \\
\hline 10 & Germany & 41 & 652 & 15.9 & 45 \\
\hline 11 & Italy & 29 & 369 & 12.7 & 33 \\
\hline 12 & Japan & 28 & 457 & 16.32 & 34 \\
\hline 13 & Sweden & 27 & 432 & 16 & 10 \\
\hline 14 & France & 18 & 415 & 23.1 & 41 \\
\hline 15 & Malaysia & 18 & 111 & 6.2 & 13 \\
\hline 16 & Russian Federation & 18 & 249 & 13.8 & 12 \\
\hline 17 & Spain & 18 & 385 & 21.4 & 21 \\
\hline 18 & Jordan & 17 & 178 & 10.5 & 3 \\
\hline 19 & Netherlands & 17 & 373 & 21.9 & 15 \\
\hline 20 & South Korea & 17 & 204 & 12 & 15 \\
\hline
\end{tabular}

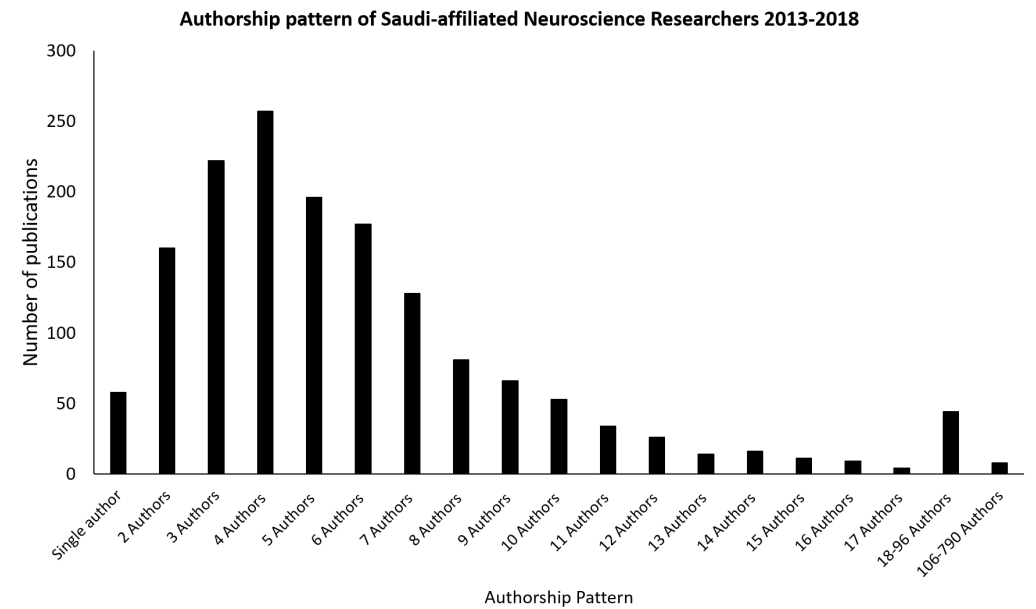

Figure 1 - Authorship patterns of Neuroscience researchers affiliated with Saudi Arabian institutions documented from January 2013 to December 2018. Four-authors pattern was found to be the most frequent one, while 2-10 authors constituted $85 \%$ of the publication during this time. 
Table 5 -Ten most preferred Journals of Neuroscience researchers affiliated with Saudi Arabia during 2013-2018.

\begin{tabular}{|c|c|c|c|c|c|c|c|}
\hline Sr\# & Source Title & Publications & Country & $\begin{array}{l}\text { Total } \\
\text { Citation }\end{array}$ & $\begin{array}{l}\text { Citation } \\
\text { Impact }\end{array}$ & Cite Score & Quartile \\
\hline 1 & Neurocomputing & 192 & Netherlands & 3198 & 16.29 & 1.07 & Q1 \\
\hline 2 & CNS \& Neurological Disorders-Drug Targets & 86 & Netherlands & 711 & 8.26 & 0.86 & Q3 \\
\hline 3 & Neural Network & 47 & United Kingdom & 1666 & 35.44 & 2.36 & Q1 \\
\hline 4 & PeerJ & 35 & United Kingdom & 58 & 3.22 & 1.09 & Q2 \\
\hline 5 & British Journal of Ophthalmology & 32 & United Kingdom & 187 & 5.84 & 2.17 & Q1 \\
\hline 6 & Canadian Journal of Neurological Sciences & 26 & United Kingdom & 68 & 2.61 & 0.55 & Q3 \\
\hline 7 & Investigative Ophthalmology and Visual Science & 25 & United States & 186 & 7.44 & 2.06 & Q1 \\
\hline 8 & Metabolic Brain Disease & 22 & United States & 124 & 5.63 & 0.91 & Q2 \\
\hline 9 & Molecular Neurobiology & 21 & United States & 93 & 4.42 & 1.61 & Q1 \\
\hline 10 & Neuropsychiatric Disease and Treatment & 20 & New Zealand & 164 & 8.2 & 0.91 & Q2 \\
\hline
\end{tabular}

institutions located in the Western region produced the majority of the neuroscience research (47.3\%) followed by the Central (39.4\%) and Eastern regions $(6.6 \%)$. Seventy-three publications were contributed by the researchers affiliated with the Southern region $(4.6 \%)$ and only three publications were produced by the researchers of the Northern region $(0.2 \%)$.

Five hundred and twelve authors contributed 1,564 publications in the targeted period and the most productive authors in the research field of neuroscience in KSA are reported in Table 3. Of the 15 most productive authors, seven authors are affiliated with KAU and another seven to KSU, and one was affiliated with King Fahad Specialist Hospital, Dammam. The author Kamal, Mohammad Amjad of KAU was the most productive, with 78 publications and an 8.8 citation impact, followed by Alsaadi, Fuad Eid S. of KAU with 65 publications, followed by Laila Youseff Al-Ayadhi of KSU with 36 publications. Five authors contributed 19 publications each and 239 others contributed 2 articles each. Ninety-three authors contributed three articles each, and 43 authors contributed four articles each.

The researchers affiliated with the KSA collaborated with scientists from 109 other countries. The majority of publications (12.3\%) were co-authored with researchers from institutions in the United States of America, followed by $10.6 \%$ publications with authors in China, the United Kingdom (5.61\%), and Canada (5.42\%). Our analysis indicates that almost one-third of collaborating countries produced more than threefourths of the total publications, while less than quarter publications produced in collaboration with two-third of all collaborating countries. A large number of publications $(78.6 \%)$ are noted to be produced in collaboration with 35 countries (32.11\%) of the world (with at least 10 publications per country). There were 74 countries $(67.9 \%)$ with $<10$ joint publications (Table 4).

Figure 1 displays the authorship pattern of 1,564 publications in neuroscience from 2013-2018. The majority of publications $(96 \%)$ are the product of collaborative research, whereas only $58(3.7 \%)$ publications were authored by single authors. A four-author pattern was found to be the most frequent co-authorship fashion with 257 (16.4\%) publications, followed by three-author pattern accounting for 222 (14.2\%) publications and five-author pattern resulting in $196(12.53 \%)$ publications. Authorship patterns from 2 to 10 co-authors produced 1,340 (85.2\%) publications, while more than 10 co-authors pattern created $166(10.61 \%)$ publications. There are eight publications with more than 100 co-authors.

The impact of a given publication can also be evaluated by the number of citations it has received. Thirteen publications included in the study received $>100$ citations. There are $356(22.7 \%)$ publications without any citation, while $175(11.7 \%)$ publications have received only one citation. Majority of publications $(\mathrm{n}=609 ; 38.93 \%)$ received 2 to 10 citations.

The top 10 sources of publication are all international research journals. A total of 1564 publications on neuroscience were published in 326 source publications/ journals. "Neurocomputing" journal of The Netherlands published the highest number of documents (192, $12 \%$ ) by Saudi Arabian authors, followed by "CNS and Neurological Disorders-Drug Targets" with 86 documents (5.5\%) and "Neural Network" with 47 documents $(3.1 \%)$. There are 133 journals with one publication each and 49 journals with two publications each (Table 5).

All publications of neuroscience were then further divided into ten subcategories determined by Scopus. 
The highest number of publications $(\mathrm{n}=437 ; 27.88 \%)$ deals with the subcategory of General Neuroscience, followed by Neurology $(n=368)$ and Cognitive Neuroscience $(n=346)$. The highest number of citations $(\mathrm{n}=6303)$ were given to Cognitive Neuroscience with 18.2 citations per publication. The lowest number of citations $(n=190)$ were received by Neuroscience (miscellaneous).

Discussion. The main objective of this study was to examine the publishing trends of Saudi neuroscience research, including the most productive and highly cited authors, institutes and journals, authorship, and collaboration patterns. We also undertook the subject dispersion under the umbrella term of neuroscience. We focused on the bibliometric analysis of the productivity of neuroscience research in KSA, covering the period from January 2013 to December 2018. For this period of time, the research in the filed of neuroscience as a subject category has not been bibliometrically reviewed in KSA previously. Our results have generated significant and new findings regarding the bibliometric dynamics of neuroscience research in the KSA. The results can be used to guide research policy and targets specified in vision 2030.

Our results include a total of 1,564 publications in the neuroscience research during the period under review, with a linear increase in publication output within the KSA over the past 6 years (Table 1). This increase is in line with the overall increase in the visibility and QS ranking of Saudi universities in recent times ${ }^{6}$ as well as in line with the overall increase in published research in the field of neuroscience in Arab world ${ }^{24}$ and worldwide, ${ }^{25}$ namely Turkey ${ }^{26}$ India, ${ }^{27}$ China, ${ }^{28}$ Pakistan, ${ }^{29}$ Africa, ${ }^{30}$ and Latin America. ${ }^{31}$ The subject of neuroscience ranks 20th when compared to other subject categories in the Saudi context. When compared globally, Saudi Arabia ranks 39th in neuroscience research productivity. This raises alarm as no Saudi author was incuded in top 10 in the categories of "most productive", "most cited" or "most cited from Muslim countries" in a bibliometric review of global Muslim Mental health research productivity during 2000-2015. ${ }^{32}$ One major factor that contributes to the relatively low rank of Saudi Arabia compared to other countries is the modest government expenditure on higher education research when compared to the research expenditure of other first world countries. Saudi Arabia spends only about $0.3 \%$ of the gross national product on research. ${ }^{33}$ The relatively low productivity may also be attributed to absence of a specialized center of excellence for neuroscience research in the KSA. For comparison, over $1 / 3$ rd of total budget of the University College of London (UCL) is accounted for neuroscience program that considers it a strategic priority. ${ }^{34}$

A comparison with the Arab world is imperative in order to understand the research progress in KSA. The review by Elie G. Karam ${ }^{24}$ in 2015 revealed that KSA produced highest number of research publications in the Arab world during 1996-2005 period while it fell to 5th place in the same category during 2006-2015. The analysis also showed that in mental health research articles per year per million population, the leading countries are Kuwait, Bahrain and Lebanon while KSA stood at 10th position. After adjusting this parameter for gross domestic product per capita, Egypt, Jordan and Tunisia are the ones on top while KSA stands at 7 th position. Other possible reasons may be a dearth of faculty members, postgraduate research programs, international students, low faculty to student ratio, and poor quality of mentorship. Few specialized labs and funding opportunities are available, which may also be a contributing factor. Although institutional requirements of research and innovation as obligations for job promotion may have increased productivity to some extent, a genuine difference can only be made by a change in policy regarding the prioritization of research areas. ${ }^{19}$ Given that research in the field of neuroscience not only improves the quality of life for those with a diagnosis of a neurological disorder but also facilitates progress in many other disciplines, such as engineering and artificial intelligence, it is imperative that this area of research be prioritized.

A comparison with advancements in neuroscience research in Africa also bears significance. In Africa, ${ }^{30}$ there is a positive correlation between GDP per capita and neuroscience research, while this doesn't apply to KSA. In addition, it is important to mention the Nigerian model. Nigeria, Africa's most populous country, has become a hub of neuroscientific research in the continent, following South Africa and Egypt. Bibliometric studies have cited annual increase in number of publications in Africa in general ${ }^{30,35}$ and in Nigeria in particular. ${ }^{36}$ The distinguishing features of neuroscientific progress in Nigeria are the involvement of neuroscience research promotors like International Brain Research Organization (IBRO), The World Academy of Sciences, The International Society for Neurochemistry, Teaching and Research in Natural Sciences for Development in Africa and Seeding labs. ${ }^{37}$ With the establishment of the Neuroscience Society of Nigeria and the introduction of Tertiary Education Trust Fund, the rich medicinal flora of the country seems ready to embrace the world challenges in 21 st 
century. The impact of these policies remains a highlight of the last 2 decades and presents an inspiration for development of neuroscience as a field of research.

Establishing an organization for Saudi neuroscience research and specialized centers for neuroscience research may provide research grants, hold annual conferences, training programs, and encourage and reward innovation. It would enable the more remote research centers, along with junior researchers, to collaborate with active investigators in the field, to receive technical support, and extend their collaborative network. Furthermore, the unification of resources, coordination initiatives, and facilitation of quality communication among research centers would prove advantageous to all neuroscience researchers. Establishing such a specialized neuroscience research center of excellence, with a dynamic environment, high-quality staff, specialized postgraduate programs, focused efforts, and a vision to develop neuroscience research, would greatly improve the current state of research in this category.

King Abdulaziz University and King Saud University, located in the western and central regions of KSA, respectively, were among the highest producers (Table 2). These universities were established in the year 1967 and 1957, respectively. Older institutions attract international faculty members and students given the well-established research culture and overall reputation. In contrast to Western and Central regions, institutions from the rest of Saudi Arabia, specifically the Eastern, Southern, and Northern regions, were less productive (Table 2). The national policymakers need to give these regions and the instuitions therein special attention, incentives, and funding to raise their level of research productivity.

The ease of international communication in the 21 st century facilitates collaboration across borders. Estimating the current state of networking and collaboration across disciplines and institutions may be a way of quantifying the research productivity of academia. Another metric that could prove useful in this regard is the number of authors who participate in a given publication. More than $80 \%$ of the publications included in this study listed 2-7 authors with faculty members from the USA, China, and the UK as the top contributors to Saudi researchers' collaborative ventures in terms of the number of publications. However, our results indicate that collaborations with France, Spain, and the Netherlands received better citation impact, whereas joint publications with Egypt and Malaysia have generated the lowest citation impact (Table 5). These statistics may help to focus on more productive collaborations in the future.
A given author's choice of target journal varies according to the journal scope, acceptance rate, processing and publication fees, and the impact factor. Observation of the pattern of the type of journals in which the majority of Saudi neuroscience researchers have published can be used to indicate the focus of most of their research. Top journals publishing Saudi neuroscience research include journals such as Neurocomputing, CNS and Neurological DisorderDrug Target, and Neural Network. This implies that computational neuroscience, as well as patent-oriented research, are priorities. The concept of a universityindustry linkage and knowledge-based economy is based on the same idea: that academia should take a practical approach in research. Surprisingly, none of the Saudi journals were among the top 10 sources of publication identified in our study, which highlights the need to improve local journals so that they become more desirable to authors.

As for the subject categorization of subfields of neuroscience, cognitive and general neuroscience remain the most frequently published fields. However, the field of developmental neuroscience remains one with comparatively fewer publications. Genetic and developmental disorders remain a high priority worldwide. For example, autism is listed as the top-cited term worldwide. ${ }^{38}$ While this area is indeed a priority in $\mathrm{KSA},{ }^{39}$ developmental neuroscience as a subfield still requires an increase in attention and focus.

Comparing the top institutions of Saudi Arabia to IAU, the current authors' institution, yields encouraging statistics. The IAU contributed $4.4 \%$ of the total publications recorded in the reviewed period compared to Alfaisal University, with a contribution of $6.31 \%$, which has an appreciably higher number of faculty members.

Neuroscience in 21st century has emerged as an indicator of scientific growth and social development because of its wide application and potential for future industrial and scientific growth. ${ }^{38}$ The new initiative and vision launched by the ministry of education in 2017 to motivate institutions to publish high-quality research is an excellent first step in striving to improve the status of biomedical research in KSA. ${ }^{40}$ Supportive leadership with a visionary approach that will encourage quality of research and publication impact in addition to focusing on quantity is highly important. ${ }^{30}$ Further, institutions should be encouraged to place an emphasis on the publication impact (i.e. quality) rather than merely the quantity of publications. ${ }^{38}$

Currently, most of the research programs that focus on neuroscience at postgraduate levels are clinically 
oriented and tend to focus on clinical training instead of research. Therefore, courses on research methodology should be included within medical and applied medical science curriculum to expose the students to a research environment early in their career. Undergraduate students should be encouraged to participate in research projects and be provided with opportunities to facilitate experience and confidence. To achieve that, emphasizing applied research skills for students enrolled in undergraduate programs, especially the professional ones including Bachelor of Medicine, Dentistry, and Veterinary Sciences should prove beneficial.

Should the implementation of such a program occur, the consideration of factors that can negatively influence research output must be given high priority. Some potentially detrimental factors include lack of funding and support and lack of proper access to the available resources. Moreover, monitoring of other factors that influence the progress of research such as smooth regulations and polices to biological samples ordering, reduction of the time gap for release of funds as well as delivery of scientific equipment, will further enhance research productivity.

The responsibility of young scientists and senior academics is to transfer the acquired knowledge and creative ideas to implement new research mindset, follow research ethics, implement flexible and researchfriendly guidelines, provide healthy motivating work environment, increased investment in capacity building and as a result, construct a devoted, valued, passionate workforce.

Our findings can be used to guide a research policy for neuroscience. By highlighting collaboration and publication patterns, identifying regions and subcategories that need attention and support, we have made it easy for the policymakers to set their priorities right.

Limitations of Study and Future Research Directions. The study is limited to the publications indexed in SciVal feature of Scopus on the subject area of Neuroscience and authors affiliated with KSA published from January 1, 2013 to December 31, 2018. It was beyond the scope of our study to ascertain whether the included research was carried out in KSA or not. Moreover this is purely a quantitative study, and citation analysis and quality of publication of the included research were not analyzed. Saudi researchers working outside KSA but with no current affiliation inside the Kingdom may have been omitted. Other databases like Web of Science, PubMed, and Google Scholar may have some other records which were not included. Future research with broader criteria of inclusion encompassing wider period of research and including citation analysis of the research can help analyze remaining bibliometric aspects of neuroscientific research in KSA.

Conclusion. This study successfully documents patterns and growth of neuroscience research in the KSA that has not been documented earlier. A steady increase has been observed in the number of publications. Substantial regional and international collaboration is noted. Most productive institutions and authors are based in the central and western regions. We have made concrete suggestions for future policymaking regarding a need to focus on developmental neuroscience. Centers of excellence are needed to boost research in this area. Eastern, Southern, and Northern regions need support in terms of research strategy and uplifting of existing labs. Given the modest growth of research in the field Neuroscience, comparing productivity in the KSA with the global neuroscience community sheds light on the necessity for continued assessment of progress in this area.

Acknowledgement. The authors would like to thank Editage (https://www.editage.com) for English language editing

\section{References}

1. Enache E, Marin C, Vechiu C. The Knowledge Based Economy. SSRN Electroni J 2009.

2. Kneller R. Intellectual property rights and university-industry technology transfer in Japan. Sci Public Policy 1999; 26: 113-124.

3. Nezu R, Chou SK, Ganguli P, Nithad K, Nishio K, Tansinsin LG, et al. Technology transfer, intellectual property and effective university-industry partnerships: the experience of China, India, Japan, Philippines, the Republic of Korea, Singapore and Thailand. [Internet] Geneva: WIPO World Intellectual Property Organization; 2007. [cited 10 August 2019].

4. Markram H. Seven challenges for neuroscience. Funct Neurol 2013; 28: 145-151.

5. Adolphs R. The unsolved problems of neuroscience. Trends Cogn Sci 2015; 19: 173-175.

6. Albhaishi A, Wahsheh HA, Alghamdi T. Evaluating Web Ranking Metrics for Saudi Universities. Zaytoonah Univ Int Eng Conf Des Innovaion Sustain 2014; 1-8.

7. Lancho-Barrantes BS, Guerrero-Bote VP, Moya-Anegón F. What lies behind the averages and significance of citation indicators in different disciplines? J Inf Sci 2010; 36: 371-382.

8. Marx W, Bornmann L. Bibliometrics in research evaluation background, significance, and limitations. Soz Welt-Zeitschrift Fur Sozialwissenschaftliche Forsch Und Prax 2015; 66: 161.

9. Haeffner-Cavaillon N, Graillot-Gak C. The use of bibliometric indicators to help peer-review assessment. Arch Immunol Ther Exp (Warsz) 2009; 57: 33-38. 
10. World Health Organization. [Internet]. Mental health action plan 2013 - 2020, WHO. [cited 28 November 2019]. Available from: https://www.who.int/mental_health/publications/ action_plan/en/

11. Karthikeyan G, Manoharan A, Swaminathan S. A Scientometric Study on Neuro Science with Special Reference to Growth of Literature. Indian J Inform Sources Serv 2019; 9: 77-79. [cited 28 November 2019].

12. Tadmouri GO, Tadmouri NB. Biomedical research in the Kingdom of Saudi Arabia (1982-2000). Saudi Med J 2002; 23: 20-24.

13. Al-Khalifa HS. Scientometric assessment of Saudi publication productivity in computer science in the period of 1978-2012. Int J Web Inf Syst 2014; 10: 194-208.

14. Rabaan AA, Al-Ahmed SH, Bazzi AM, Al-TawfiqJA. Dynamics of scientific publications on the MERS-CoV outbreaks in Saudi Arabia. J Infect Public Health 2017; 10: 702-710.

15. Shehatta I, Mahmood K. Bibliometric patterns and indicators of research collaboration of Egyptian health scientists: 1980. Malays J Lib Info Sci 2017; 22: 45-65.

16. Al-Bishri J. Evaluation of biomedical research in Saudi Arabia. Saudi Med J 2013; 34: 954-959.

17. Rohra DK, Rohra VK, Cahusac P. Institute for Scientific Information-indexed biomedical journals of Saudi Arabia: Their performance from 2007-2014. Saudi Med J 2016; 37: 1251-1257.

18. Jamjoom A. State of clinical neuroscience research in Saudi Arabia: where do we rank in the world? Neurosciences (Riyadh) 2016; 268-270.

19. Algahtani H, Shirah B, Boker F, Algamdi A, Alkahtani A. Neurology research in Saudi Arabia: Urgent call for action. Sultan Qaboos Univ Med J 2017; 17: e324-e328.

20. Jamjoom AA, Jamjoom BA, Jamjoom AB. The most cited Saudi neurosurgical publications. Neurosciences (Riyadh) 2013; 18: 83-86.

21. Jamjoom AB. Survey of h-index for neurosurgeons in Saudi Arabia. Neurosciences (Riyadh) 2015; 20: 392-395.

22. Baeesa SS, Maghrabi YE, Baeesa MS, Jan FM, Jan MM. Publications pattern of clinical epilepsy research in Saudi Arabia. Neurosciences (Riyadh) 2017; 22: 255-260.

23. Haq I, Al Fouzan K. Research Productivity at King Saud bin Abdul Aziz University for Health Sciences, Kingdom of Saudi Arabia: A Bibliometric Appraisal. J Rawalpindi Med Coll 2017; 21: 182-186.

24. Karam EG, Itani LA. Mental health research in the Arab world: an update. BJPsych Int 2015; 12: S-25-28.

25. Buchan AMJ, Jurczyk E, Isserlin R, Bader GD. Global neuroscience and mental health research: a bibliometrics case study. Scientometrics 2016; 109: 515-531.
26. Kocak M, García-Zorita C, Marugán-Lázaro S, Çakır MP, Sanz-Casado E. Mapping and clustering analysis on neuroscience literature in Turkey: a bibliometric analysis from 2000 to 2017. Scientometrics 2019; 121: 1339-1366.

27. Shahabuddin SM. Mapping neuroscience research in india - A bibliometric approach. Curr Sci 2013; 104: 1619-1626.

28. Xu W, Chen YZ, Shen ZC. Neuroscience output of China: A MEDLINE-based bibliometric study. Scientometrics 2003; 57 : 399-409.

29. Farooq RK, Syed Z, Zulqernain A. Bibliometric review of mental health research in medical colleges of Pakistan. Sultan Qaboos Univ Med J 2019; 19: e242-e247.

30. Abd-Allah F, Kissani N, William A, Oraby MI, Ramez Reda Moustafa RR, Shaker E, El-Tamawy MS, Shakirf R. Neuroscience research in Africa: Current status. eNeurologicalSci 2016; 3: 7-10.

31. Altalib HH, Elzamzamy K, Fattah M, Ali SS, Awaad R. Mapping global Muslim mental health research: analysis of trends in the English literature from 2000 to 2015. Glob Ment Heal 2019; 6.

32. Albilad Capital. Saudi Public Budget for FY17 [Internet]. Saudi Economy; 2016. [cited 26 December 2016]. Available from: http://www.albilad-capital.com/Research_EnglishReport/ SaudiPublicBudget_EN_2016.pdf

33. Forero DA, Trujillo ML, González-Giraldo Y, Barreto GE. Scientific Productivity in Neurosciences in Latin America: A Scientometrics Perspective. Int J Neurosci 2019; 1-2 (Epub ahead of print).

34. Smart T. UCL Research Domains Neuroscience. [cited 28 November 2019]. Available from: https://www.ucl.ac.uk/ research/domains/neuroscience/about-us, 2019-

35. Quansah E, Karikari TK. Neuroscience-related research in Ghana: A systematic evaluation of direction and capacity. Metab Brain Dis 2016; 31: 11-24.

36. Balogun WG, Cobham AE, Amin A. Neuroscience in Nigeria: the past, the present and the future. Metab Brain Dis 2018; 33: 359-368.

37. Maina MB, Mohammed YG, Bukar AM, Ahmed U, Tajjani Salihu A, Ibrahim HA, et al. African neuroscience on the global stage: Nigeria as a model. Eur J Neurosci 2019; 49: 1544-1551.

38. Yeung AK, Goto TK, Leung WK. The changing landscape of neuroscience research, 2006-2015: a bibliometric study. Front Neurosci 2017; 11: 120.

39. Alkuraya FS. Genetics and genomic medicine in Saudi Arabia. Mol Genet Genomic 2014; 2: 369-78.

40. Alsayea A. Scientific Research in the Kingdom of Saudi Arabia: Potential for Excellence and Indicators of Underdevelopment. High Educ Stud 2013; 3: 47-51. 